\title{
Low dose choline chloride in cerebellar degeneration
}

\author{
CA AUSTIN, KI MUNDY, S DOREY \\ From the Departments of Neurology and Pharmacy, Royal Hallamshire Hospital, Sheffield, UK
}

SUMMARY Sixteen patients with cerebellar degeneration were treated with oral choline chloride for six weeks at doses of 3 and $6 \mathrm{~g}$ daily. Two patients improved with choline but another four improved with placebo. Choline chloride in a dose of 3-6 $\mathrm{g}$ daily is no better than placebo in improving ataxia due to cerebellar degeneration.

Relative deficiency of brain acetylcholine (ACh) may be the cause of ataxia in Friedreich's ataxia and other forms of cerebellar degeneration.' Recently, the therapeutic potential of replenishing brain ACh by orally administered choline has been investigated..$^{2-5}$ In man and animals oral choline produces an increase in blood, CSF and brain choline levels. $^{6-10}$

A patient with idiopathic cerebellar degeneration showed clinical improvement in ataxia whilst treated with choline chloride. ${ }^{2}$ Subsequent trials of choline in ataxia due to cerebellar and spinocerebellar degeneration have been disappointing. A double blind study of 20 patients receiving 6 or $12 \mathrm{~g}$ choline chloride daily showed mild improvement in upper limb ataxia in 10 patients and in lower limb and gait ataxia in two patients. There was a $50 \%$ incidence of side effects at the higher dose, and no correlation between blood choline levels and clinical response was demonstrated. ${ }^{3}$ In another double blind study one of 13 patients treated with $4 \mathrm{~g}$ daily of choline chloride showed a dose dependent reproducible improvement in upper limb and gait ataxia. ${ }^{4}$ Postulated mechanisms for this improvement are increased ACh synthesis or a direct postsynaptic effect of choline. ${ }^{3}$

We report the results of a double blind crossover trial of low dose (3-6 g/day) choline chloride in patients with cerebellar degeneration in which we hoped to demonstrate an objective improvement in ataxia without incurring side effects.

Address for reprint requests: Dr CA Austin, Department of General Medicine, Royal Hallamshire Hospital, Sheffield S10 2RX, UK.

Received 31 October 1983 and in revised form 23 March 1984 Accepted 24 March 1984

\section{Patients and methods}

The trial was approved by the local ethical committee. Eleven patients with cerebellar degeneration and five with spinocerebellar degeneration were studied (table 1). None of the patients had clinical evidence of posterior fossa neoplasm, carcinoma, alcohol abuse and thyroxine or vitamin $B_{12}$ deficiency. Fourteen patients had normal serum vitamin $B_{12}+$ folic acid levels and 13 had normal thyroxine levels. CT scans with Conray enhancement were performed in 12 patients, of whom six showed cerebellar atrophy and seven had normal scans. Lumbar puncture was performed where indicated clinically in five patients and the CSF in these patients was normal. Medications prescribed before the trial were unchanged during the study period.

The trial was double blind. Choline chloride or placebo were dispensed as liquid mixtures. The placebo mixture contained $140 \mathrm{ml}$ raspberry syrup and $9 \mathrm{ml}$ concentrated chloroform water (BPC 1959) made up to $350 \mathrm{ml}$ with distilled water. The choline mixture contained in addition $70 \mathrm{~g}$ choline chloride. Sufficient placebo or choline mixture was dispensed for 3 weeks treatment at a dose of $5 \mathrm{ml}$ or $10 \mathrm{ml}$ thrice daily (tds), an allowance being made for spillage due to ataxia.

Each patient was randomly allocated to one of two treatment groups. Group I received $5 \mathrm{ml}$ tds of choline mixture ( $3 \mathrm{~g}$ choline/day) for three weeks, then $10 \mathrm{ml}$ tds ( $6 \mathrm{~g}$ choline/day) for the second three week period. Group two received $5 \mathrm{ml}$ tds of placebo mixture for three weeks, then $10 \mathrm{ml}$ tds for the second three week period. At six weeks groups I and two were crossed over. The total study period was 12 weeks.

Each patient was assessed prior to treatment and at three weekly intervals during the trial by the same investigator, giving five assessments per patient. At each visit the patient's symptoms were recorded and a standard clinical assessment of ataxia was performed. Upper limb ataxia was also assessed by comparing handwriting, spiral copying, rapid dotting, and straight line drawing tests. Both hands were tested unsupported.

At the end of the study period, prior to knowledge of the treatment group, each patient's five assessments were 
Table 1 Clinical details of patients.

\begin{tabular}{|c|c|c|c|c|c|c|}
\hline No. & Sex & Age (yr) & Diagnosis & Treatment group & Response & Side effects \\
\hline 1 & $\mathbf{M}$ & 44 & spinocerebellar degeneration & I & - & - \\
\hline 2 & $\mathbf{M}$ & 68 & cerebellar degeneration & I & - & - \\
\hline 3 & $\mathbf{F}$ & 16 & cerebellar degeneration & II & $C(6 g>3 g)$ & - \\
\hline 4 & $\mathbf{M}$ & 59 & cerebellar degeneration & I & $-\left(0_{5}-36\right)$ & - \\
\hline 5 & $\mathbf{F}$ & 54 & cerebellar degeneration & I & $\bar{P}$ & - \\
\hline 6 & $\mathbf{F}$ & 34 & cerebellar degeneration & I & $\mathbf{P}$ & Headache (P) \\
\hline 7 & $\mathbf{F}$ & 68 & cerebellar degeneration & II & $C(3 g>6 g)$ & - \\
\hline $8^{*}$ & $\mathbf{F}$ & 47 & spinocerebellar degeneration & I & - & Headache (C) \\
\hline 9 & $\mathrm{~F}$ & 44 & spinocerebellar degeneration & II & - & - \\
\hline 10 & $\mathbf{F}$ & 25 & spinocerebellar degeneration & II & - & - \\
\hline 11 & $\mathbf{M}$ & 48 & spinocerebellar degeneration & I & - & - \\
\hline 12 & $\mathbf{M}$ & 72 & cerebellar degeneration & I & - & Headache (P) \\
\hline 13 & $\mathbf{M}$ & 61 & cerebellar degeneration & I & $\mathbf{P}$ & - \\
\hline 14 & $\mathbf{M}$ & 65 & cerebellar degeneration & II & - & - \\
\hline 15 & $\mathbf{F}$ & 57 & cerebellar degeneration & I & - & Headache (P) \\
\hline 16 & $\mathbf{M}$ & 56 & cerebellar degeneration & I & $\mathbf{P}$ & - \\
\hline
\end{tabular}

*patient withdrawn from trial prior to receiving placebo.

$\mathrm{C}=$ on choline, $\mathrm{P}=$ on placebo.

analysed for symptomatic and clinical improvement in ataxia and for side effects.

In an attempt to quantify results of the rapid dotting test, the mean dot distance (MDD) in millimetres from the circumference of the $2 \mathrm{~mm}$ diameter target was calculated for each assessment in 12 patients. The mean of the MDD values for all 12 patients pre-treatment, on choline chloride and on placebo, were compared using Students' paired $t$ test. A $\mathrm{p}$ value of $<0.05$ was taken to be significant.

\section{Results}

Patient 8 developed severe headache and was withdrawn from the trial; hence, 15 patients completed the full trial. The results of the mean MDD for all 12 patients pre-treatment, on placebo and on choline, are shown in table 2 . No significant difference was found between the treatment groups. Four patients felt they had improved on placebo $(5,6,13,16)$, but this improvement was only demonstrable clinically in two patients $(5,16)$. However, their MDD values showed no improvement. Of the remaining 11 patients, two $(3,7)$ showed a modest symptomatic and clinical improvement in upper limb ataxia with choline and in both cases their MDD values improved by $50 \%$. This was more marked on $6 \mathrm{~g}$ daily in patient 3 and on $3 \mathrm{~g}$ daily in patient 7 . Clinically it was felt the improvement of patients 3 and 7 was greater than of patients 5 and 16 . Patient 14 reported a deterioration in ataxia following withdrawal of choline at the end of the trial.

Three patients $(6,12,15)$ reported headache whilst taking placebo. Patient 8 developed headache whilst taking choline ( $3 \mathrm{~g} /$ day) and the headache disappeared on withdrawing choline. No other side effects were reported.

\section{Discussion}

Two patients $(3,7)$ of the 15 completing the full trial showed modest symptomatic, clinical, and quantitative improvement with choline; but another two (5, 16) showed improvement on placebo and a further two $(6,13)$ felt symptomatically better on placebo.

We were unable to demonstrate an improvement in ataxia with choline chloride at doses $3-6 \mathrm{~g} /$ day, but found a low incidence of side effects. This may be because choline is ineffective in treating ataxia, because we studied too few patients or because the dose range used was inappropriately low.

We feel that, at present, the use of choline chloride in the treatment of cerebellar ataxia cannot be recommended. Oral lecithin had been shown in human studies to raise serum choline levels higher and for longer periods than choline in equivalent amounts." Further studies in this area using lecithin

Table 2 Mean MDD values in millimetres

\begin{tabular}{|c|c|c|c|c|c|}
\hline & Pre-Treatment & Placebo for $3 / 52$ & Placebo for $6 / 52$ & Choline $3 \mathrm{~g}$ for $3 / 52$ & Choline $6 \mathrm{~g}$ for $3 / 52$ \\
\hline $\begin{array}{l}X \\
\text { SEM } \\
S \\
S^{2}\end{array}$ & $\begin{array}{l}3.29 \\
1.057 \\
2.276 \\
5.18\end{array}$ & $\begin{array}{l}3.05 \\
0.659 \\
1.797 \\
3.229\end{array}$ & $\begin{array}{l}3.411 \\
0.503 \\
1.570 \\
2.465\end{array}$ & $\begin{array}{l}3.188 \\
0.706 \\
1.799 \\
3.236\end{array}$ & $\begin{array}{l}2 \cdot 806 \\
0 \cdot 490 \\
1 \cdot 516 \\
2 \cdot 298\end{array}$ \\
\hline
\end{tabular}

$\mathrm{X}=$ Mean MDD.

SEM = Standard Error of the Mean

$\mathbf{S}=$ Standard Deviation.

$\mathbf{S}^{2}=$ Variance. 
in larger numbers of patients are needed.

We thank Dr JPP Bradshaw, neurologist, Royal Hallamshire Hospital, Sheffield, for his advice and encouragement during this work, and $\mathrm{Dr} G A$ Davies-Jones and Dr EJ Gumpert for allowing us to treat their patients.

\section{References}

' Barbeau A, Butterworth RF, Ngo T, et al. Pyruvate metabolism in Friedreich's ataxia. Can J Neurol Sci 1976;3:379-88.

${ }^{2}$ Legg NJ. Oral choline in cerebellar ataxia. $\mathrm{Br}$ Med J 1978;2: 1403.

' Livingstone IR, Mastaglia FL, Pennington RJT, Skilbeck C. Choline chloride in the treatment of cerebellar and spinocerebellar ataxia. J Neurol Sci 1981;50:161-74.

+ Lawrence CM, Millac P, Stout GS, Ward JW. The use of choline chloride in ataxic disorders. $J$ Neurol Neurosurg Psychiatry 1980;43:452-4.

${ }^{5}$ Philcox DV, Kies B. Choline in hereditary ataxia (letter). Br Med J 1979;2:613.

${ }^{\circ}$ Cohen EL, Wurtman RJ. Brain acetylcholine: control by dietary choline. Science 1976;191:561-2.

7 Aquilonius SM, Eckernas SA. Plasma concentration of free choline in patients with Huntingdon's chorea on high doses of choline chloride. $N$ Engl $J$ Med 1975; 293: 1105-6.

${ }^{*}$ Hollister LE, Jenden DJ, DoAmard JR, Barehas J. Plasma concentrations of choline in man following choline chloride. Life Sci 1978;23:17-22.

" Growdon JH, Cohen EL, Wurtman RJ. Huntingdon's disease. Clinical and chemical effects of choline administration. Ann Neurol 1977;1:418-22.

${ }^{10}$ Davis KL, Berger PA. Pharmacological investigations of the cholinergic imbalance hypothesis of movement disorders and psychosis. Biol Psych 1978; 13:23-49.

" Wurtman RJ, Hirsch MJ, Growdon JH. Lecithin consumption raises serum free choline levels. Lancet 1977;2:68-9. 